\title{
APONTAMENTOS PARA CONSTRUÇÃO DE UMA METODOLOGIA \\ DE ENSINO DE FILOSOFIA A PARTIR DO INTERACIONISMO \\ SIMBÓLICO DE GEORGE HERBERT MEAD E DO AGIR \\ COMUNICATIVO DE JÜGEN HABERMAS
}

\section{NOTES FOR CONSTRUCTING A TEACHING METHODOLOGY OF PHILOSOPHY FROM SYMBOLIC INTERACTIONISM OF GEORGE HERBERT MEAD AND COMMUNICATIVE ACTION OF JÜGEN HABERMAS}

\author{
José Gilliard Santos da Silva \\ Shirlene Santos Mafra Medeiros ${ }^{2}$
}

Recebido em: 05/2018

Aprovado em: 07/2018

\begin{abstract}
Resumo: O objetivo do presente trabalho consiste em apontar as algumas contribuições do Interacionismo Simbólico de George Herbert Mead e do agir comunicativo de Jürgen Habermas, para se pensar uma metodologia de ensino de filosofia, orientada numa perspectiva de identificação, investigação epistemológica e busca por soluções de problemas, tendo o diálogo como fio condutor dessa proposta.

Palavras-chave: Irracionalismo simbólico, Ensino de Filosofia, Metodologia, Mead.
\end{abstract}

\begin{abstract}
The objective of the present work consists in pointing out the few contributions of the symbolic interactionism of George Herbert Mead and communicative action of Jürgen Habermas, to think about a teaching methodology of philosophy, oriented with a view to identification, epistemological investigation and finding solutions to problems, having the dialogue as conductor of this proposal.

Keywords: Symbolic Interactionism, Teaching Philosophy, Methodology, Mead.
\end{abstract}

\footnotetext{
1 Mestrando em Filosofia pelo Programa de Mestrado Profissional em Filosofia- PROF-FILO da Universidade Federal do Paraná (UFPR) em parceria com a Universidade do Estado do Rio Grande do Norte (UERN), sob orientação da professora Dra. Shirlene Santos Mafra Medeiros, e professor de Filosofia da SEEC-RN. Professor do quadro permanente da SEEC-RN. Email: gilliardsantos2014@outlook.com

${ }^{2}$ Dra. Shirlene Santos Mafra Medeiros. Pedagoga - UFRN, Especialista em Formação de Professores numa perspectiva Interdisciplinar- UFRN, Gestão Educacional; Mestre em Ciências Sociais - UFRN e Doutora em Memória, Linguagem e Sociedade - UESB; Professora do Departamento de Filosofia - Campus Caicó- UERN, Orientadora do Mestrado Profissional em Filosofia da Universidade do Estado do Rio Grande do Norte- UERN. Email: shirlenemafra@yahoo.com.br
} 


\section{Introdução}

O despertar das pesquisas em Habermas, surge nas discussões em sala de aula no período da graduação de filosofia da disciplina "Filosofia Contemporânea II", "Atividades Filosóficas V", onde foi oportunizado estudos de "Habermas e a Educação"; sobre a possibilidade e viabilidade de experienciar vivências educativas com a pedagogia hermenêutica crítica emancipativa no interior da instituição escolar, em que permite a formação social do sujeito crítico, reflexivo e a sua autoformação de memórias experienciais intersubjetivas no "olhar para si" e para "o outro" e os "cuidados de si" no processo de interações sociais, cujas bases teóricas são de Jürgen Habermas e de George Herbert Mead.

Diante da tarefa quixotesca da filosofia, de conquistar o seu lugar, numa sociedade marcadamente utilitarista e individualista, aponta-se como caminho para a filosofia e seu ensino, a partir da possibilidade de construir uma metodologia de ensino-aprendizagem, que enfatizará o caráter interativo dialógico da filosofia na busca por solução de problemas do cotidiano, bem como a necessidade de pensar a educação a partir de duas perspectivas distintas, mais inseparáveis: a formação social e intersubjetiva do sujeito e do caráter central da comunicação como fio condutor das relações entre os sujeitos (agir comunicativo). Tomando como base a conjuntura econômica e social na qual nosso modelo educacional (modelo tecnicista e de fragmentação e especialização de conhecimentos) está inserido e que pelo qual é determinado, bem como a necessidade de apontar alternativas para a superação desse paradigma, surge uma interrogação inevitável: que modelo ou proposta de educação deve ser adotada ou construída, que possibilite sujeito a uma formação integral, crítica e emancipativa?

Diante do exposto, a presente comunicação fará alguns apontamentos para a construção de uma metodologia de ensino de filosofia alicercada no pensamento de G. H. Mead e J. Habermas. Num primeiro momento será abordado alguns elementos conceituais e metododológicos do interacionismo simbólico na perspectiva medeana, e suas possíevis contrubuições para o ensino de filosofia. Em seguida, será apresentado alguns pressupostos a respeito do papel da ação comunicativa habermasiana como elemento central de uma prática educatica.

\section{Interacionismo simbólico e ensino de filosofia}


Iniciaremos pela análise dos conceitos de interacionismo simbólico, presente no pensamento de George Herbert Mead. Em alguns momentos será feito o diálogo com o pensamento de Jürgen Habermas e a sua Teoria do Agir Comunicativo. Na tentativa de buscar caminhos para a elaboração e aplicação de uma metodologia de ensino de filosofia no Ensino Médio, que será norteada pela construção e participação coletiva dos envolvidos (estudantes e professor), onde as experiências individuais, os valores morais, o contexto social, os significados construídos e reconstruídos pelos atores envolvidos no processo, serão levados em consideração para a criação da referida metodologia, optou-se pela abordagem teórica do Interacionismo Simbólico, que como afirma Dalbosco (2017, p. 629) implica em entender "[...] a ação humana compreendida como interação mediada simbolicamente para pensar a educação como um processo de reconhecimento recíproco[..].” Deve-se a Herbert Blumer a apresentação do conceito de Interacionismo Simbólico ao campo das teorias sociais e da filosofia, muito embora seus fundamentos tenham sido construídos pelo professor de Blumer, George Herbert Mead. Como afirma o próprio Blumer (1980, p. 125),

Devemos a George Herbert Mead a mais penetrante análise da interação social [...] Mead identifica duas formas ou níveis de interação social na sociedade humana. Refere-se aos mesmos como "a conversação dos gestos" e "o uso de símbolos significantes", que neste ensaio serão denominados "interação não simbólica" e "interação simbólica", respectivamente. (BLUMER, 1980, p. 125)

Portanto, apesar de Mead não utilizar especificamente o conceito de Interacionismo Simbólico, como afirma Medeiros (2016, p. 32), a ênfase de seus estudos "da consciência, da ação, da interação do processo da formação humana", contribui para a construção do conceito anos mais tarde apresentado por Blumer. Como pondera Medeiros (2016, p. 87), “Assim, pode-se compreender, que o pressuposto introdutório do Interacionismo simbólico inicia com Mead e a sistematização do nome, princípios e perspectivas forma delineados por Herbert Blumer".

Uma vez que, as interações sociais são pontos fundamentais na perspectiva do Interacionismo Simbólico, cumpre destacar que essas interações ou relações sociais não se configuram com simples relações mecânicas, causa e efeito, nem tão pouco se constituem como regras ou parâmetros gerais pré-estabelecidos. Pelo contrário, as interações sociais de definem como processo contínuo, dinâmico, com influências mútuas e constante transformação. Como afirma Joas (1999, p. 130), 
O caso prototípico é o das relações sociais em que a ação não adota a forma a forma de mera transferência de regras fixas em ações, mas em que as definições das relações são, recíproca e conjuntamente, propostas e estabelecidas. Assim, as relações socais são vistas, não como algo estabelecido de uma vez por todas, mas como algo aberto e subordinado ao reconhecimento contínuo por parte dos membros da comunidade. (JOAS, 1999, p. 130)

Assim como o pensamento de Mead e de Blumer estão associados ao pragmatismo, o Interacionismo Simbólico tem suas raízes no contexto do desenvolvimento da pesquisa sociológica ${ }^{3}$ nos Estados Unidos, e mais especificamente na Universidade de Chicago, berço da teoria pragmática. Como assegura Joas (1999, p. 131),

O significado real do interacionismo simbólico e sua potencial fecundidade teórica só podem ser compreendidos quando contrastado com a velha Escola de Chicago, a quem dão continuidade, embora omitindo alguns aspectos de seu pensamento. [...] O interacionismo simbólico é visto como como a continuação de certas partes do pensamento e obra do heterogêneo grupo interdisciplinar de teóricos, pesquisadores e reformadores sociais da Universidade de Chicago que exercem certa influência na sociologia americana entre 1890 e 1940, durante a fase de institucionalização propriamente dita da disciplina. (JOAS, 1999, p. 131)

Essa relação do Interacionismo Simbólico com o pragmatismo, pode ser percebida no valor que ambas concedem à ação, mais especificamente a ação interativa e social, com vistas a romper com a clássica separação entre consciência e matéria, corpo e mente. Nesse sentindo, Joas (1999, p. 132-133) afirma que "O pragmatismo é uma filosofia da ação. [...] desenvolveu o conceito de ação a fim de superar os dualismos cartesianos. Desse empreendimento surgiu uma compreensão da intencionalidade e da sociabilidade radicalmente diferente da compreensão do utilitarismo." Ainda sobre a relação entre filosofia pragmática da ação e Interacionismo Simbólico, insiste Joas (1999, p. 167), “[...] o pragmatismo introduziu o conceito de ação como meio de obter uma nova visão de relação entre a ação e a consciência, ou seja, como meio de superar a filosofia da consciência [...]." Blumer (1980, p. 119), ao definir o conceito de Interacionismo Simbólico, aponta algumas premissas básicas para a sua fundamentação:

\footnotetext{
${ }^{3}$ Apesar do predomínio das pesquisas sociológicas nos primórdios da Escola de Chicago, uma outra vertente de estudos orientada pela filosofia e psicologia desenvolvida por G. H. Mead, como afirma Howard Becker (1996, p. 183), "Outra vertente explorada em Chicago foi a de psicologia social. O filósofo George Herbert Mead foi aqui muito influente. Mead era um filósofo, não um sociólogo, e um de seus interesses era a relação entre a mente, o self e a sociedade, o que, aliás, é o título de seu livro mais conhecido.
} 
A primeira premissa é a de que os seres humanos agem em relação às coisas com base nos significados que as coisas têm para eles (...) A segunda premissa é a de que o significado destas coisas origina-se na, ou resulta da, interação social que uma pessoa tem com as demais. A terceira premissa é a de que esses significados são controlados em um processo interpretativo e modificados através desse processo, que é utilizado pela pessoa para lidar com as coisas com as quais se depara. (BLUMER, 1980, p. 119)

Essas "coisas" que os seres humanos agem de acordo com o significado que lhe são apresentados, ou mais especificamente, que são construídos pelos sujeitos, referem-se a qualquer fenômeno ou coisa que o ser humano pode observar ou definir dentro de suas experiências. Como destaca Blumer (1980, p. 111),

Tais elementos (ou coisas) abrangem tudo o que é possível o homem observar em seu universo - objetos físicos, como árvores ou cadeiras; outras pessoas, como mães ou balconistas; categorias como seres humanos, como amigos ou inimigos; instituições como escolas ou o governo; ideais norteadores, como independência individual ou honestidade; atividades alheias, como ordens ou solicitações de outrem -, além das situações com que o indivíduo se depara em seu dia a dia. (BLUMER, 1980, p. 111)

Portanto, o ser humano em vivências cotidianas, em seus processos interativos, suas experiências corriqueiras orientam suas ações e relações de acordo com os significados que tais ações apresentam para ele.

Ainda sobre os fundamentos do Interacionismo Simbólico, Blumer (1980, p. 123), afirma que,

O interacionismo simbólico fundamenta-se em uma série de conceitos básicos, ou "imagens-raiz", como preferimos denominá-los. Tais imagensraiz referem-se à e descrevem a natureza dos seguintes problemas: grupos ou sociedades humanas, interação social, o homem como agente, atividade humana e conjugação das linhas de ação. Tomadas em conjunto, tais imagens-raiz representam a maneira pela qual o interacionismo simbólico considera a sociedade e o comportamento humano, constituindo' nossa estrutura de estudo e análise. Passemos então à descrição' sucinta de cada uma dessas imagens-raiz. (BLUMER, 1980, p.123)

Além das premissas apontadas por Blumer, a professora Rita Radl Philipp, da Universidade de Santiago de Compostela, apresenta mais dois pontos importantes a respeito dos estudos sobre o Interacionismo Simbólico. Para Philipp (1996, p. 104) a tradição do Interacionismo Simbólico de ser per compreendida, 
[...] com vista as possibilidades para explicar os processos, mecanismos de mudanças que intervém na estrutura das sociedades modernas e aponta dois pontos fundamentais: que o Interacionismo simbólico não é uma tradição uniforme e não podemos considerar uma escola ou teoria no sentido estrito; o outro ponto aborda uma linha teórica que segue as premissas básicas de George Herbert Mead, cujos pontos principais das análises da realidade social não constituem objetos expressos das reflexões dos enfoques fenomenológicos. (PHILIPP, 1996, p. 104)

As segunda e terceira premissas, respectivamente, apontam para o modo como os significados das "coisas" são construídos no âmbito das interações sociais, num processo de cooperação, de construção e reconstrução continua, no seio das experiências dos sujeitos no seu lugar de pertença.

A afirmação de Blumer (1980, p. 11) que "o significado destas coisas origina-se na, ou resulta da, interação social que uma pessoa tem com as demais", implica dizer que ideias, conceitos, valores, só se constituem no contexto das interações sociais, ou seja, não carregam nenhum valor ou significação anterior a interação entre sujeitos. Como defende Blumer (1980, p. 121), a perspectiva do Interacionismo Simbólico,

[...] considera que o significado é produzido a partir do processo de interação humana. Para um indivíduo, o significado de um elemento nasce da maneira como outras pessoas agem em relação a si no tocante ao elemento. Todas as suas ações preocupam-se em defini-lo para o indivíduo. Dessa forma o interacionismo simbólico considera os significados produtos sociais, criações elaboradas em e através das atividades humanas determinantes em seu processo interativo. (BLUMER, 1980, p.121)

A argumentação de Blumer encontra fortes elementos no pensamento meadiano. Isso pelo fato de que Mead vai defender que o indivíduo começa a criar significado para suas ações no contexto do diálogo de gestos significantes, ou seja, a linguagem que é a base para a comunicação e para as interações sociais. Como afirma Mead (2010, p. 84) “Quando falamos do significado do que estamos fazendo, estamos concretizando a resposta de que estamos prestes a executar um estímulo para a nossa ação. " Para Mead (2010) o significado consiste em algo que existe de forma objetiva, como uma relação entre certas fazes de um ato social. ${ }^{4}$ Portanto, ao assumir que o sentido e o significado de ideias, valores, normas ou conceitos, são

\footnotetext{
4 "Ato social pode ser definido como aquele em que a ocasião ou estímulo que libera um impulso é encontrado no caráter ou conduta de uma forma viva que pertence ao ambiente próprio a essa forma viva da qual é o impulso. Entretanto, desejo restringir o ato social à classe de atos que envolve a cooperação de mais de um indivíduo, e cujo objeto, definido pelo ato, no sentido de Bergson, é um objeto social. (MEAD, 2010, p. 18)
} 
construídos socialmente, deve-se entender que só se é possível haver significado numa determinada ação ou ato social, se tal significado for validado pelos sujeitos envolvidos na ação. Na concepção meadiano (2010), a construção de um significado se dá na forma de um tripé, onde se tem em um organismo, que define o gesto do primeiro sujeito, o segundo organismo, responsável pelo segundo gesto e num terceiro lugar encontra-se o ato social, que corresponde ao espaço onde se dão tais interações. Tal interação se dá em termos de ajustamento de ações. Nesse sentido afirma Mead (2010, p. 90),

Quer dizer, os objetos são constituídos em termos dos significados dentro do processo social da experiência e do comportamento, por meio de ajustamentos mútuos de resposta ou atos de vários organismos individuais envolvidos no processo uns com os outros, um ajustamento que se tornou possível por meio de uma comunicação que assume a forma de um diálogo de gesto nas formas preliminares desse processo e de linguagem, nos posteriores. (MEAD, 2010, p. 90)

Ainda sobre a natureza triádica do significado de um gesto, num determinado ato social, Blumer (1980, p. 126) defende que,

[...] pode-se verificar que o significado do gesto percorre três caminhos (a natureza triádica do significado de Mead): significa o que a pessoa para quem é destinado deve fazer o que a pessoa que o apresenta tenciona realizar, é a ação conjunta originada da articulação dos atos de ambos. Desta forma à guisa de um exemplo, a ordem de um ladrão à sua vítima para erguer as mão constitui (a) indicação do que a vítima tem de fazer, (b) indicação do que o ladrão planeja executar, isto é, tirar o dinheiro da vítima e (c) indicação do ato conjunto em formação, no presente assalto. (BLUMER, 1980, p. 126)

É necessário observar que, em qualquer ato social, se uma dessas fases (interação triádica) não for observada, não se pode afirmar que houve significado ou comunicação consciente. Como acentua Blumer (1980, p. 126), “ Se porventura houver confusão ou malentendido no decurso de qualquer uma destas três linhas de significado, a comunicação não se efetiva, impede-se a interação e bloqueia-se a feitura do ato conjunto."

Portanto, sentido e significados nas experiências dos sujeitos, na perspectiva meadiano, são formulados em termos de resposta e de ajustamento. Por isso seu caráter interativo e intersubjetivo. Assim, as ações humanas e seus respectivos significados, não constituem um simples processo imitativo de assimilação e transmissão de valores e significados. Como defende Carreira da Silva (2009, p. 173), "Muito mais importante [...], é o 
fato de que, quando um organismo age, sua conduta tem o significado implícito de uma determinada resposta a outro organismo. " Logo, a comunicação (sentido e significado) entre os seres humanos, surgiu num processo de cooperação, onde um sujeito elabora sua resposta numa determinada situação com vistas ao gesto do outro sujeito. Assim, de acordo com Mead (2010, p. 91), os objetos e seus significados são "Constituídos no seio do processo social da experiência pela comunicação e por mútuos ajustamentos de comportamentos. ”

Podemos afirmar, então, que o processo de elaboração de sentidos e significados na vida dos sujeitos se dão somente, no contexto das interações sociais e que, constituem o ponto de partida para construção de um processo comunicativo que possibilita a compreensão dos diversos tipos de ações e objetos que fazem do contexto das inúmeras formas de organização social. E tal processo de compreensão se dá somente, não âmbito da tomada de papeis entre os sujeitos que determinam a si mesmo e a outra pessoa. É pela comunicação (linguagem) que o ser humano cria o mundo e lhe dota de sentido. Como afirma Casagrande ((2012, p. 37-38)

\begin{abstract}
Para que exista comunicação, em qualquer atuação linguística é fundamental um processo de compreensão. Ou seja, é necessário que cada um entenda o que disse e, ao mesmo tempo, sinta-se afetado pela mensagem proferida do mesmo modo que essa mensagem afeta os receptores. A comunicação consiste, portanto, no princípio básico de organização da comunidade humana e do processo de individuação. [...] A comunicação responde pelo sentido da organização social de um grupo humano específico e, ao mesmo tempo, pelo caráter ético das ações dos diversos indivíduos sociais. [...]A comunicação cria mundo, visto que o mundo é construção simbólica, criação comum na linguagem e no entendimento recíproco. A sociedade dota o mundo de significado. A comunicação faculta às diversas sociedades formas de organização específicas e, aos seus integrantes, atitudes coerentes às circunstâncias sociais e históricas nas quais estão inseridos e implicados. Além disso, através da comunicação, os homens adquirem a capacidade de organizar simbolicamente as mais distintas condutas possíveis. Ou seja, mediante a comunicação é possível que os diversos seres humanos, tanto individualmente, quanto em comunidade, articulem as próprias ações e, ao mesmo tempo, levantem pretensões em relação às condutas recíprocas. (CASAGRANDE, 2012, p. 37-38)
\end{abstract}

Para Mead, portanto, e para a perspectiva teórica do Interacionismo Simbólico, o ser humano se constitui e se define em sua dimensão social e no espaço de suas experiências e ações, tudo possibilitado por um processo de comunicação simbolicamente mediada, que permite a construção do comportamento, da identidade, da consciência e da inteligência (racionalidade) humana. Nas palavras de Mead (2010, p. 399) "O homem é uma criatura racional por que é uma criatura social." Por isso, para Mead, não é possível falar em mente, 
consciência ou inteligência em termos apriorísticos, ou seja, fora da dimensão interativa e linguística, como afirma Mead (2010, p. 58) “A existência da mente ou inteligência só é possível em termos de gestos como símbolos significantes. " Pois, é justamente nas interações sociais que os sujeitos se propõem a adotar a atitude do outro na constituição de seu comportamento, valores, regras ou conceitos. Dessa forma, afirma Mead (2010, p. 58), "E, e todas as conversas externas de gestos (entre diferentes indivíduos) ou internas (da pessoa consigo mesma), a consciência individual do conteúdo e do fluxo do significado depende de o indivíduo adotar, em relação a seu próprio gesto, a atitude do outro. " Tal processo, só é possível num contexto social, interativo e intersubjetivo.

\section{O Interacionismo simbólico e suas contribuições para filosofia e a educação.}

Como foi demonstrado até o momento, não se pode compreender o Interacionismo Simbólico fora das relações sociais, das interações entre os sujeitos, de uma linguagem de gestos significantes que possibilite a construção de significados, de compreensão nas experiências cotidianas. Nesse sentido, não se pode negar que tais fundamentos sociais estejam dissociados nos processos educativos. Educação e sociedade são duas faces de uma mesma moeda. Pensar a educação em Mead $^{5}$ e em Habermas ${ }^{6}$ é pensar a ação educativa como uma ação essencialmente social. E que, o ambiente escolar deve ser compreendido a partir do contexto das experiências sociais, históricas, econômicas e políticas dos diversos atores que fazer o espaço escolar. Tal contexto deve ser orientado pela prática do diálogo e das relações interativas entre atores envolvidos nesse processo, cabe observar que um dos pontos que merecem uma significativa atenção, é o modo como são resolvidos os problemas ou conflitos (individuais ou sociais, objetivos ou subjetivos), que se fazem presentes no cotidiano de todos os sujeitos. Nessa perspectiva, Casagrande (2012, p. 78),

[...] faz-se necessário, entre outros elementos: criar espaços e instâncias de comunicação sem coação; optar pelo agir comunicativo, mesmo que

\footnotetext{
${ }^{5}$ É importante observar que apesar de Mead discutir a problemática da Educação, nunca chegou de fato a elaborar ou publicar uma obra contemplando essa temática. O tema da educação encontra-se em artigos e aulas ministradas na Universidade de Chicago e anotada pelos seus alunos.

${ }^{6}$ Habermas não esboça em sua produção teórica uma análise sobre a educação ou escola propriamente dito. $\mathrm{O}$ que se faz, são análises da educacionais fundamentadas em seu pensamento. Como afirma Bannell (2006, p. 15), "Cabe aqui observar mais um esclarecimento: a aplicação do pensamento de Habermas para prática pedagógica na escola é um caminho cheio de armadilhas e dificuldades. Que eu saiba, o próprio Habermas nunca escreveu nada sobre a escola [...] Os únicos textos dele sobre instituições de ensino são análises das funções da universidade na sociedade contemporânea [...]."
} 
tenhamos consciência de que é impossível agir o tempo todo visando ao entendimento e à justificação racional das falas e ações; aderir ao discurso racional como modo de elucidação dos problemas oriundos do mundo objetivo, social e subjetivo; organizar processos de aprendizagem com vistas ao acréscimo de racionalidade e ao aumento da competência comunicativa dos atores sociais; promover processos de individuação social sob a perspectiva do agir comunicativo e da interação. (CASAGRANDE, 2012, p. 78)

A proposta para resolução de problemas do cotidiano, com base na inteligência como na solução de problemas ou pelo agir comunicativo de Habermas, passa pela necessidade de construção de uma proposta de relacionamento comum entre os diversos sujeitos ou atores sociais, alicerçada pelo diálogo aberto e sem coerção, onde todos têm a possibilidade de apresentar e defender seus argumentos, resultando desse processo a construção de valores morais e sociais coletivos. Consiste, portanto, numa ideia de educação que possibilite a quebra das correntes de um modelo educacional marcadamente tecnocrata, que direciona o sujeito, única e exclusivamente para formação de mão de obra, visando sanar as demandas oriundas de uma sociedade orientada pelos interesses do capital. Tal modelo de educação apenas acentua as desigualdades sociais e divisão de classes. Mead tece uma crítica ferrenha ao modelo de educação planejado e financiado pela indústria nos Estados Unidos. Como afirma Carreira da Silva (2009, p. 194),

Nas levas de imigrantes que acorreram à Chicago naquela época, as indústrias encontram a solução para suas necessidades: os "capitães da indústria" viram na educação técnico industrial a única forma de prover treinamento profissional para as classes trabalhadoras, já que as faculdades e universidades de artes dedicavam-se à formação das classes altas da sociedade. (CARREIRA DA SILVA, 2009, p. 194)

No entendimento de Mead um sistema educacional de ensino, não deveria ser planejado, orientado e financiado por setores privados (empresas, indústrias, bancos, etc.), pelo simples fato de que tais setores apenas tinham o interesse de resolver seus problemas de formação de mão de obra, negando uma educação mais ampla que possibilitasse aos sujeitos um olhar mais crítico e contestador de sua própria situação individual e social. Um sistema que aprofundava a divisão social de classes. Mais de cem anos depois, as ideias de Mead permanecem atuais e significativas, principalmente no contexto educacional brasileiro dos últimos três anos. Uma proposta educacional para o exercício pleno da cidadania, para enfrentar e resolver os problemas do cotidiano, sejam eles morais ou materiais, eis a ideia de 
Mead para educação. Como salienta Carreira da Silva (2009, p. 195), Para Mead,

A escola é o mais importante instrumento de que dispõe uma comunidade, se ela realmente quiser dotar seus jovens das aptidões cognitivas e morais necessárias para o exercício esclarecido da cidadania. Um cidadão atuante é um indivíduo capaz de enfrentar com racionalidade os problemas sociais, de levar em consideração todos os valores em jogo e de ser capaz de reconstruir essa situação problemática transcendendo a ordem específica que vive. (MEAD, 2010, p. 195)

Como afirma Habermas (2000, p. 414) “[...] no paradigma do entendimento recíproco é fundamental a atitude performativa dos participantes da interação que coordenam seus planos de ação ao se entenderem entre si sobre algo no mundo. " Essa construção coletiva de soluções que envolve os conflitos inerentes a comunidade é essencial para o desenvolvimento de um modelo de educação crítico, emancipatório e dialógico. Ou como defende Philipp (1996, p. 129-130) "o objetivo final do agir comunicativo reside no mesmo assunto, a resolução de problemas práticos da vida, ao mesmo tempo que, através deles, são criados os conteúdos de significados e objetos de nossa atuação social"

O lugar da filosofia, num sistema educacional de uma sociedade que é orientada, quase que exclusivamente, pela lógica capitalista e técnica na produção de conhecimento, seria oferecer saberes e possibilidades que norteasse a sua vida para uma análise e compreensão de suas próprias ações, valores, conhecimentos, e que possibilitasse a construção de uma postura autônoma, crítica, dialógica e emancipatória perante aos valores e conhecimentos constituídos pela sociedade na qual está inserido. Habermas enfatiza a necessidade de um novo modelo de racionalidade a partir da análise do fenômeno da “dominação tecnocrática", onde os sujeitos não encontram espaço para o diálogo, para a reflexão ou análise crítica do próprio contexto, de suas ações e valores. Segundo Habermas (2006 b, p. 75),

\footnotetext{
A implantação moral de uma ordem sancionada e, assim, da ação comunicativa que se orienta por um sentido linguisticamente articulado e que pressupõe a interiorização de normas, é dissolvida numa amplitude cada vez maior por modos de comportamento condicionados, enquanto as grandes organizações como tais se apresentam com a estrutura da ação racional dirigida a fins. (HABERMAS, 2006b, p. 75)
}

Um dos grandes desafios de uma proposta de ensino de filosofia, que seja norteada pelo seu aspecto crítico e emancipatório é superar essa ideia, bastante enraizada de uma "ação 
social dirigida a fins" que retira do sujeito a capacidade de colocar sob suspeita os saberes e valores que orientam sua vida. Dessa forma, ao enfatizar o papel da filosofia como um conhecimento transdisciplinar, presente nas relações interativas entre os sujeitos e consolidada pelo diálogo aberto e livre, pretende-se oferecer a filosofia o papel de mediadora entre os diversos tipos de saberes, e guardiã dos aspectos racionais, críticos e emancipatórios do conhecimento. Portanto, caberia a filosofia, fornecer os saberes e pressupostos necessários para a identificação, compreensão e construção de solução para problemas quem surgem no cotidiano de sujeitos e permeia todas as sociedades. Como propõe Shook (2002, p. 138),

O aprendizado não é mero conjunto de funções psíquicas. A forma mais importante de aprendizado, essencial para o progresso da inteligência humana, é aquela que se esforça deliberadamente em desenvolver as etapas do aprendizado, algo que ocorre somente durante o ato afetivo da solução de um problema. (SHOOK, 2002, p. 138)

Portanto, a educação para solução de problemas não se revela como um simples processo mecânico que adestra os sujeitos para conjuntos previsíveis de situações problemáticas que podem ocorrer do cotidiano dos sujeitos. Pelo contrário, como afirma Shook (2002, p. 139), “A solução de problemas, quando bem-sucedida, às vezes adiciona novos fatos às crenças de uma pessoa e às vezes adiciona novas habilidades ao conjunto de habilidades de uma pessoa." Dessa forma, uma proposta de ensino de filosofia, voltada para a solução de problemas, possibilita aos sujeitos a possibilidade de construir e reconstruir uma série de valores, conhecimentos e habilidades essenciais ao sujeito no convívio social.

\section{Considerações finais}

A discussão envolvendo Habermas e Mead, consequentemente entre Agir Comunicativo e Interacionismo Simbólico, busca apresentar alternativas para a construção de uma metodologia para o ensino de filosofia no Ensino Médio, alicerçada no diálogo e nas relações interativas entre os sujeitos. Busca também mostrar a necessidade de envolver o estudante do Ensino Médio nessa busca por uma metodologia, partindo da análise das suas expectativas e interesses, de seus saberes e necessidades e do contexto social no qual está inserido. Toda essa discussão é construída com base no Agir Comunicativo, onde os atores envolvidos no processo educativo, professores, estudantes, gestão, suporte pedagógico e família, demonstrando assim o caráter interativo do processo ensino-aprendizagem. Tomando 
como referência a realização de Ágoras Filosóficas (rodos de conversas tanto na escola como outros lugares da comunidade), o ponto de partida da referida proposta metodológica seria a identificação de problemas do cotidiano do público-alvo, sempre orientado pelas suas experiências individuais e coletivas, a sua devida problematização, seguida de uma investigação epistemológica ancorada na tradição filosófica. O diálogo (agir comunicativo) como eixo central da proposta, permeará todo o trabalho, desde a identificação da problemática até a validação racional e coletiva de algumas possibilidades de soluções.

\section{Referências bibliográficas}

BANNELL, Ralph Ings. Habermas e educação. Belo Horizonte: Autêntica, 2006.

BECKER, Howard. Conferência: A Escola de Chicago. IN: MANA, 2(2), p. 177-88, 1996.

BLUMER, Herbert. A natureza do interacionismo simbólico. In: MORTENSEN, C. D. (Org). Teoria da comunicação: textos básicos. São Paulo : Mosaico, 1980.

CARREIRA DA SILVA, Filipe. Em diálogos com os tempos modernos: o pensamento político e social de G. H. Mead. Rio de Janeiro: Tempo Brasileiro, 2009.

CASAGRANDE, C. A. A formação do eu em Mead e Habermas: desafios e implicações à educação. Tese (doutorado) - Pontifícia Universidade Católica do Rio Grande do Sul Programa de Pós-Graduação em Educação. - Porto Alegre, 2012.

DALBOSCO, Cláudio Almir. Pensar a educação em tempos pós-metafísicos: a alternativa do Interacionismo simbólico. IN: Revista Educação. Santa Maria. Vol. 42. No 3. P. 629-642. Set/dez. 2017.

JOAS, Hans. Interacionismo simbólico. IN: Teoria social hoje. (Org.) Anthony Giddens e Jonathann Tuner. Tradução de Gilson César Cardoso de Sousa, - São Paulo: Editora UNESP, 1999. - (Biblioteca básica).

HABERMAS, Jürgen. Técnica e Ciência como "Ideologia". Tradução de Artur Morão. Lisboa - Portugal: Edições 70, 2006 b.

O Discurso Filosófico da Modernidade: doze lições. Tradução de Luiz Sérgio Repa, Rodnei Nascimento. - São Paulo: Martins Fontes, 2000. (Coleção Tópicos).

MEAD, G. H. Mente, Self e Sociedade. (org). Charles W. Morris. São Paulo: Ideias e Letras, 2010.

PHILIPP, Rita Maria Radal. Sociologia Crítica: Perspectivas Actuales. Madrid - Espanha: Editorial Síntesis, 1996.

SHOOK, J. R. Os pioneiros do pragmatismo americano. Tradução de Fábio M. Said. - Rio de Janeiro: DP\&A, 2002. 